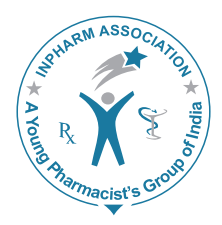

\title{
Minimizing pharmaceutical waste: The role of the pharmacist
}

\author{
Suruchi Aditya1*, Aditya Rattan² \\ ${ }^{1}$ Department of Pharmacology, Dr. Harvansh Singh Judge Institute of Dental Sciences, Chandigarh, India, \\ ${ }^{2}$ Consultant Cardiologist, Heartline, Panchkula, Haryana, India
}

\begin{abstract}
Objective: To explore the knowledge, attitudes and practice of pharmacists about medication disposal and their awareness about potential environmental effects of inappropriate drug disposal. Materials and Methods: A prevalidated, structured questionnaire with both open- and close-ended questions was distributed to a random cohort of 150 pharmacists of an urban town of North India. The questionnaire assessed disposal of leftover and expired drugs by pharmacists and their knowledge of drug disposal by the distributors. The awareness of the correct method of drug disposal, ways to minimize the pharmaceutical waste and extent of dissemination of information about drug disposal to patients was also evaluated. Results: The response rate was $56 \%$. Although majority of the pharmacies have a system to dispose expired and leftover drugs, the knowledge about disposal was found to be incomplete. Most of the leftover drugs belonging to different dosage forms were returned to the distributor. One-third pharmacists did not know the correct method to dispose drugs. Majority of them did not advise patients about disposal of unused drugs. Only $58 \%$ believed that improper drug disposal is intimately connected to environmental pollution. Conclusion: Pharmacists have new roles and responsibilities to function as collaborative members of healthcare team by disseminating information about correct ways to dispose unused drugs.
\end{abstract}

Key words: Active pharmaceutical ingredient, drug disposal, pharmacist

\section{INTRODUCTION}

Leftover and expired drugs, an indirect measure of wasted healthcare resources, reflect lost opportunities to achieve therapeutic outcomes (either due to incorrect choice or noncompliance) and a burden for the environment. In addition, medication waste is costly to national health systems because

\begin{tabular}{|c|c|}
\hline \multicolumn{2}{|c|}{ Access this article online } \\
\hline Journal Sponsor & \multirow[b]{2}{*}{$\begin{array}{l}\text { Website: } \\
\text { www.jyoungpharm.org }\end{array}$} \\
\hline \multirow{2}{*}{ wuw.phcog net } & \\
\hline & $\begin{array}{l}\text { DOI: } \\
\text { 10.5530/jyp.2014.3.3 }\end{array}$ \\
\hline
\end{tabular}

of the costs of purchasing and proper disposal of the unused medication subsequently. While annual drug wastage amounts to about $f^{3} 300 \mathrm{~m}$ in England, consumers in United States (US) wasted more than $\$ 418$ billion in 2012 due to suboptimal drug use. ${ }^{1,2}$ According to the Central Pollution Control Board of India, registered healthcare facilities generate 4,057 tonnes of waste/day. ${ }^{3}$ The pharmaceutical waste stream includes expired products, dispensed drugs that are unwanted or discontinued, and contaminated medications. Household drug wastage remains unquantified; disposal of drugs, including those with addictive potential (controlled drugs) such as opioids has been found to be improper among patients, reflecting that proper advice on prudent and responsible medication disposal is lacking, and there is a pressing need to create awareness on this issue.

Address for correspondence:

Dr. Suruchi Aditya, Department of Pharmacology, Dr. Harvansh Singh Judge Institute of Dental Sciences, Chandigarh, India.

E-mail: suruchiaditya@rediffmail.com 
Active pharmaceutical ingredients are ubiquitous contaminants in the environment with their unintended presence in sewage, surface and ground waters and other ecosystems. Pharmaceuticals, their metabolites, transformation products, as well as the excipients and additives, enter the environment by different routes via several sources such as manufacturing plants, household waste disposal, effluents of sewage treatment plants and land-fill. ${ }^{4}$ In a study by Cantrell $e t$ al. that measured the amounts of the active ingredients in the medications which had expired 28-40 years ago, 12 of the 14 active ingredients persisted in concentrations that were $90 \%$ or greater of the amount indicated on the label and retained their full potency for 336 months or longer. ${ }^{5}$ Although pharmaceuticals tend to be present in relatively low levels in the ecosystem, and the results of short-term exposure to humans seem to be minimal, the subtle results of long-term exposure to low levels of pharmaceutical waste remain unknown. ${ }^{4}$ In a study by Ramaswamy et al. high levels of carbamazepine and triclosan were detected in surface waters of Kaveri, Tamiraparani and Vellar rivers of Kerala. ${ }^{6}$ Brodin et al. showed that exposure of wild European perch (Perca fluviatilis) to oxazepam at concentrations encountered in effluent-influenced surface waters $(1.8 \mu \mathrm{g} / \mathrm{L})$ led to increased activity, reduced sociality, and higher feeding rate. ${ }^{7}$ Thomas $e t$ al. observed that unmetabolized psychoactive pharmaceuticals induce autism-like gene expression patterns in fish, suggesting a new potential trigger for idiopathic autism implicating a source of environmental contamination. ${ }^{8}$

World Health Organization has introduced the concept of seven star pharmacists that comprise the qualities of a caregiver, the decision maker, communicator, manager, lifelong learner, teacher, and leader. ${ }^{9}$ Being respected, trusted and most accessible drug information resources, pharmacists are in the forefront of tackling issues of prudent drug disposal methods to end users of drugs. All pharmacists should familiarize themselves with their region's drug disposal activities and be able to recommend them to their patients. Unused, expired or returned drug products require proper disposition and accountability as per Food and Drug Administration (FDA), which gives a list of 26 drugs to be disposed of by flushing. ${ }^{10}$ The present study was undertaken to assess the knowledge regarding proper drug disposal and the practice of disposal of leftover/expired drugs by the pharmacists. The study also examined the extent of dissemination of knowledge about drug disposal to patients by the pharmacists.

\section{MATERIALS AND METHODS}

This was a descriptive, cross-sectional survey exploring the knowledge, attitudes and practice regarding drug disposal by pharmacists. The participants were a cohort of pharmacists working in pharmacies in an urban town in North India chosen by simple random sampling method. The self-developed, anonymous, structured questionnaire containing both open- and close-ended questions had five sections: Demographic characteristics; methods adopted by pharmacists for disposal of leftover drugs; knowledge regarding how the pharmaceutical distributors dispose of the returned drugs; the possible environmental impact of improper disposal of unused drugs by patients; opinion of pharmacists about the best method to adopt to minimize pharmaceutical wastage. Before distributing the questionnaire in its final form, it was pre-tested on a group of five pharmacists, and minor modifications were made to make it easily understandable.

Respondents were assured that there was no risk involved in the study and that information obtained would be kept confidential and anonymous. There was no pointer in the questionnaire that could disclose the identity of the participant. Written informed consent was obtained from all the participants. They were given a choice to participate or refuse to do so. The researcher distributed the questionnaires to the pharmacists, and they were briefed about the nature of the study. The filled questionnaire, as well as the informed consent form, was collected in separate envelopes the next day in a closed envelope in a locked box, to assure anonymity. Post collection, the data collected from all respondents was analyzed using simple descriptive statistics.

\section{RESULTS}

Eighty-four pharmacists filled the questionnaire, giving a response rate of $56 \%$. The sample comprised mostly of males $(98 \%, n=82)$ aged between 28 and 67 years. Majority of the pharmacists held a diploma in pharmacy and were experienced in practice of pharmacy (Table 1).

Most of the leftover drugs were returned to the distributor, irrespective of dosage form. The pharmacists reported that they had adopted a systematic management strategy at their worksites to take stock of leftover drugs. One-fourth of pharmacists admitted that they trashed the solid dosage forms, especially if the quantity was less (Table 2). Most of the pharmacists $(90 \%, n=76)$ have a system to regularly remove the expired drugs from inventory. $89 \%(n=75)$ pharmacists stated that they were not taught about proper 
drug disposal in pharmacy schools. Many pharmacists were not clear $(21-37 \%)$ as to how the pharmaceutical distributors dispose of drugs, though more than half of the respondents were confident that incineration was done for solid dosage forms, controlled and hazardous drugs (Table 3).

The expired and unused drugs at the pharmacy comprised of those expired at pharmacy $(72 \%)$, returned drugs that were unsuitable to the patients leading to change of medication by the doctor $(25 \%)$ or belonging to deceased relative $(3 \%)$. The patients' frequency of enquiry about advice on drug disposal was never (98\%), sometimes (2\%), always $(0 \%)$. Majority of the pharmacists thought $(72 \%$, $n=60)$ pharmacies in government hospitals to be most suitable location for returning medications. Other places suggested were pharmacies in private hospitals or clinics $(13 \%)$, supermarket $(24 \%)$ and others $(6 \%)$. Most of the pharmacists took help of journals or workshops to get update information (Figure 1). However, knowledge about drug disposal and environmental impact of pharmaceutical waste was found to be inadequate. $58 \%(n=48)$ admitted that drug disposal was linked to environmental pollution.

Table 1: Socio-demographic data

\begin{tabular}{lc}
\hline Parameter & $\mathbf{N}(\%)$ \\
\hline Age (years) & $6(7)$ \\
$20-30$ & $29(34)$ \\
$31-40$ & $32(38)$ \\
$41-50$ & $13(15)$ \\
$51-60$ & $4(5)$ \\
$61-70$ & \\
Gender & $82(98)$ \\
Male & $2(2)$ \\
\hline Female & \\
Qualification & $9(11)$ \\
\hline Graduate course in pharmacy & $69(82)$ \\
Diploma course in pharmacy & $6(7)$ \\
\hline Other & \\
Experience as pharmacist (years) & $6(7)$ \\
\hline 10 & $57(68)$ \\
$11-20$ & $17(20)$ \\
\hline $21-30$ & $4(5)$ \\
\hline $31-40$ & \\
\hline
\end{tabular}

Table 2: Method of disposal of expired/leftover medication by pharmacists (single option was marked)

\begin{tabular}{lccccc}
\hline $\begin{array}{l}\text { Type of } \\
\text { preparation }\end{array}$ & $\begin{array}{c}\text { Garbage } \\
(\%)\end{array}$ & $\begin{array}{c}\text { Sink/ } \\
\text { toilet } \\
(\%)\end{array}$ & $\begin{array}{c}\text { Incineration } \\
(\%)\end{array}$ & $\begin{array}{c}\text { Return to } \\
\text { distributor } \\
(\%)\end{array}$ & $\begin{array}{c}\text { Other } \\
(\%)\end{array}$ \\
\hline Solids & $24(29)$ & - & - & $58(69)$ & $2(2)$ \\
Semi-solids & $13(15)$ & - & - & $71(84)$ & - \\
Liquids & $4(5)$ & $4(5)$ & - & $72(86)$ & $4(5)$ \\
$\begin{array}{l}\text { Controlled } \\
\text { drugs }\end{array}$ & $1(1)$ & - & $2(2)$ & $79(94)$ & $2(2)$ \\
P-listed drugs & $3(4)$ & - & $2(2)$ & $78(93)$ & $1(1)$ \\
\hline
\end{tabular}

$69 \%(n=58)$ could logically deduce that incineration was the best way to dispose unused/expired drugs (Table 4). Most of the respondents $(73 \%)$ agreed that drug-take backs should be regular events to manage unwanted medications. More than half of respondents acknowledged that redistributing usable drugs, short-term dispensing and educating public were good options to minimize wastage (Figure 2).

\section{DISCUSSION}

\section{Awareness about proper disposal techniques}

Our results show that the majority of the pharmacists have an active system in place for managing expired medications and pharmaceutical waste. Inventories are made regarding soon-to-expire medications, which are periodically reviewed, and most of the medications are returned to the pharmaceutical distributor. However, despite the adequate practical work, there is a lack of awareness about proper

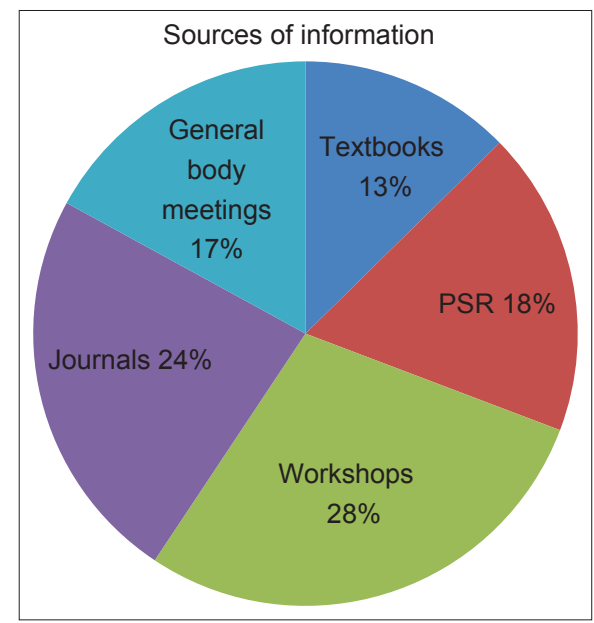

Figure 1: How pharmacists keep themselves updated (multiple responses chosen). PSR: Pharmaceutical sales representative

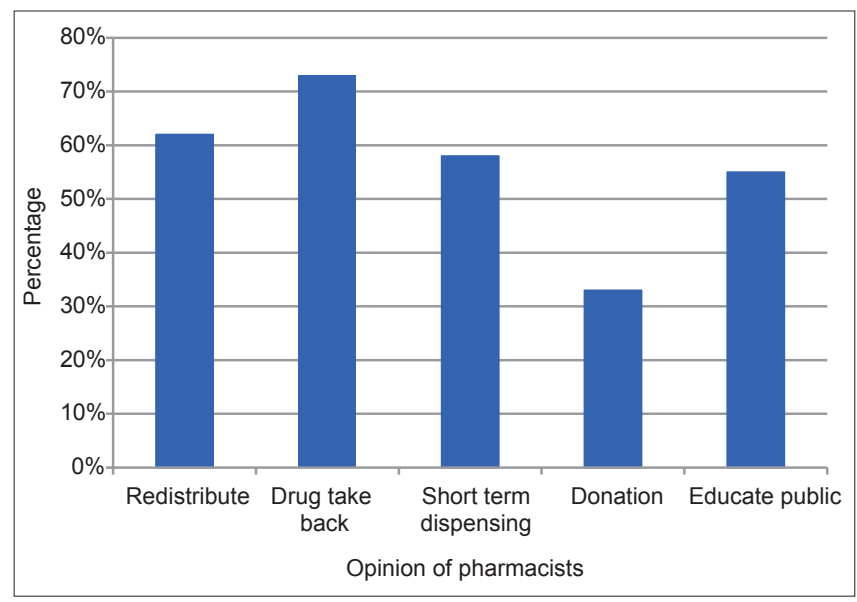

Figure 2: Ways to minimize pharmaceutical wastage (multiple responses chosen)

Journal of Young Pharmacists Vol 6 • Issue 3 • Jul-Sep 2014 
Aditya and Rattan: Pharmacist's role in minimizing pharmaceutical waste

Table 3: Knowledge of pharmacists regarding disposal of retuned drugs by pharmaceutical distributors (single option marked)

\begin{tabular}{|c|c|c|c|c|c|}
\hline Type of preparation & Dispose to landfill (\%) & Incineration (\%) & Waste encapsulation/inertization (\%) & Flushing (\%) & I do not know (\%) \\
\hline Solids & $46(55)$ & $41(49)$ & $21(25)$ & $4(5)$ & $21(25)$ \\
\hline Semi-solids & $41(49)$ & - & $12(14)$ & - & $31(37)$ \\
\hline Liquids & $31(37)$ & - & $21(25)$ & $36(43)$ & $27(32)$ \\
\hline Controlled drugs & $16(19)$ & $56(67)$ & $14(17)$ & $4(5)$ & $23(27)$ \\
\hline P-listed waste & $12(14)$ & $62(74)$ & $4(5)$ & $3(4)$ & $18(21)$ \\
\hline
\end{tabular}

Table 4: Knowledge of pharmacists regarding various aspects of drug disposal

\begin{tabular}{lc}
\hline $\begin{array}{l}\text { Statement about knowledge } \\
\text { regarding drug disposal and its } \\
\text { environmental effects }\end{array}$ & $\begin{array}{c}\text { Percentage of } \\
\text { pharmacists marking } \\
\text { correct answer (\%) }\end{array}$ \\
\hline $\begin{array}{l}\text { Improper drug disposal affects the } \\
\text { environment and ecosystem }\end{array}$ & $49(58)$ \\
$\begin{array}{l}\text { Wastewater treatment removes } \\
\text { most of the drugs } \\
\text { It is acceptable to dispose solid } \\
\text { and semi-solid drugs in garbage }\end{array}$ & $47(56)$ \\
$\begin{array}{l}\text { It is acceptable to dispose liquid } \\
\text { medications by sink }\end{array}$ & $28(33)$ \\
$\begin{array}{l}\text { It is acceptable to dispose liquid } \\
\text { medications by flushing }\end{array}$ & $46(55)$ \\
$\begin{array}{l}\text { Incineration is the environmentally } \\
\text { sound way of drug disposal }\end{array}$ & $47(56)$ \\
\hline
\end{tabular}

drug disposal. Today, the role of the pharmacist has evolved from that of a compounder and dispenser of pharmaceutical products to that of the provider of patient care (drug therapy manager). ${ }^{11}$ There is need for a paradigm shift in pharmacy practice from product-oriented to patient-oriented services. The latter encompasses empowering and enabling patients to dispose of drugs prudently. Current FDA guidelines on the proper disposal of prescription drug recommend that unused/leftover/expired medicines should not be flushed down the toilet or drain. Solid medications should be mixed with unappealing substances such as kitty litter or coffee grounds, put into a disposable container, and placed in the trash or disposed via community drug take-back programs. ${ }^{10}$ Liquid medicines should be mixed with salt, flour, charcoal, or nontoxic powdered spice, such as turmeric or mustard, to give the mixture an unappealing smell and texture. Medicines in blister packs should be wrapped in multiple layers of opaque tape, and then placed inside an opaque container for sealing. The lid of the medication bottle should be sealed with duct tape or packing tape, the medication bottle(s) should be placed inside a container that is not see-through and disposed of in the trash after sealing. ${ }^{10}$

A study in Kuwait reported trash as the common disposal route used by pharmacists $(73 \%) .{ }^{12}$ Another study in New Zealand reported third party contractors as the most common route of disposal for unused solid and semi-solid formulations; liquid (44.7\%) and class B medications (58\%) were disposed down the pharmacy sink. ${ }^{13}$ Further, about one- third respondents in our study did not know the fate of the drugs collected by the distributor. As specified by Resource Conservation and Recovery Act, special disposal techniques are needed for controlled substances, anticancer drugs, antiseptics and disinfectants and antibiotics. Hazardous waste (P and U listed pharmaceuticals) must be incinerated under supervision of a pharmacist or police depending on national regulations. ${ }^{9}$ The regulations applicable are based on waste generator status; generators of $<1 \mathrm{~kg}$ of acutely hazardous waste or $<100 \mathrm{~kg}$ of hazardous waste in a month are classified as conditionally exempt small quantity generators. They are required to identify, segregate, document and dispose waste in a state-licensed facility. The best method for medication disposal is incineration because, even with proper disposal in the trash, the pharmaceutical waste may eventually leak into the ground. Post incineration, ashes are deposited in leak proof containers bound for special landfills dealing in pharmaceutical waste. Highly engineered sanitary landfills (that place waste directly into a land disposal site), are isolated from watercourse and kept much above the water table. A major reason for noncompliance with environmental regulations may result from a lack of knowledge of the laws and rules that apply. Availability of formalized guidelines for medicine disposal is a major influence on drug disposal by end users of drugs. In a study by Jarvis et al., a brief educational intervention in the form of a newsletter sent to pharmacists improved knowledge (from $47 \%$ to $57 \% ; P=0.03$ ) and changed their attitude regarding proper disposal. ${ }^{14}$ The onus for preventing pharmaceutical waste does not lie with physicians or government agencies alone. By counseling on proper medication use, pharmacists can educate patients on the importance of taking their medications as directed, leading to an increase in adherence while minimizing the need for disposal at the same time.

\section{Drugs and the environment}

It is now well-known that medication have afterlives as environmental pollutants and that most water treatment plants and septic systems are not equipped to remove pharmaceuticals from the waste water. Three classes of drugs that pose serious threat are non-steroidal antiinflammatory drugs, hormones and antibiotics. ${ }^{4}$ Antibiotics in the effluent could increase selection pressure and 
promote the transfer of resistance genes from harmless environmental microbes into deadly pathogens, leading to the emergence of deadly drug-resistant microorganisms.

Antidepressants like selective serotonin reuptake inhibitors, calcium channel blockers and antineoplastic drugs are known to have potential for long-term aquatic effects. ${ }^{4}$

In our study, only $58 \%$ pharmacists acknowledged that drugs adversely affect environment and ecosystems. Colborn $e t$ al. have reported that exposure to endocrine disrupting chemicals (byproducts of industrial waste) are associated with abnormal thyroid function, decreased fertility, decreased hatching success and alteration of immune function in birds and feminization of male fish. ${ }^{15}$

\section{Pharmacists and continuing professional development (CPD)}

Majority of the pharmacists $(89 \%)$ stated that they were not taught disposal techniques in pharmacy schools. The new paradigm for pharmacy requires that pharmacists are more than experts in pharmaceutical chemistry and pharmaceutics. ${ }^{11}$ Radical changes in pharmaceutical education are need of the hour; curriculum restructuring should include dissemination of knowledge about proper drug disposal. In contrast to our study, in a survey of 261 first-year student pharmacists from the three schools of pharmacy in North Carolina, more than $90 \%$ of the students responded that inappropriate medication disposal can cause public health and environmental problems. Of the students, $77.4 \%$ indicated that they would go to a pharmacist to learn about proper medication disposal and $97.7 \%$ of students expected to learn about medication disposal while in pharmacy school. ${ }^{16}$

CPD requires involvement in learning activities that promote a positive attitude toward life-long learning, and this should be instilled early in the curriculum. ${ }^{11}$ Attending conferences, seminars, workshops, and webinars to learn more about this topic will play a vital role in preserving and protecting the environment for future generations.

\section{Pharmacists' opinion about the best way to minimize pharmaceutical wastage}

Pharmacists in our study expressed their willingness to conduct take-back events. Drug-take backs and mail-back programs are community-based initiatives to collect unused medicines from the public and channelize them for proper environmentfriendly disposal. Certain countries define a legal obligation of pharmacies to participate in take-back schemes. Maine's drug take-back program distributes postage-paid disposal kits containing postage-paid envelope, an instruction packet, and a survey to participating pharmacies throughout the state. Unused medications are placed inside the envelope and returned to the Maine Drug Enforcement Agency, where they are destroyed. As of April 2010, the program had disposed of more than 2,300 pounds of unwanted medications. ${ }^{17}$ Smart Rx Disposal is an online resource initiative started by American Pharmacist Association that gives free information about drug disposal on its website (www.smarxtdisposal. net) to the public. Pharmacies should plan take-back events and publicize them to encourage patients to return unused drugs. Student pharmacists can play an important role by acting as facilitators of educational campaigns. ${ }^{18}$ One of the recommended strategies to minimize pharmaceutical waste is short-cycle dispensing. Regulations in US require all pharmacies servicing long-term care facilities to dispense drugs to patients in 14 day increments at a time and also to report the type of drug dispensed. ${ }^{19}$ By implementing centrally accessible electronic medical records of patients and systems that can readily check the inventory stock of pharmacies, such as a waste inventory spreadsheet that can catalog the types and quantities of leftover medication in a central database, alterations in prescribing and dispensing practices can be made. In the "trial prescription program," patients receive a 7-day supply of medication and a reminder card on which the dispensing pharmacist records the date and time of the second visit when the patient would be contacted to evaluate the results of the "trial." Patients who tolerate the medication can receive the balance of their original prescription. ${ }^{20}$

Pharmacists $(63 \%)$ in our study acknowledged that the redistribution of usable drugs is a feasible idea that should be implemented. Returned and reusable medications provide opportunities for reduced cost of drugs for patients. "Reverse distribution" is a system in which unused, but potentially usable pharmaceuticals are returned to the manufacturer for credit. ${ }^{21}$

Studies show that previously counseled respondents are more likely to return the medication to the pharmacy. In a study, $80.3 \%$ patients never received advice on medication disposal from a health care provider. ${ }^{22}$ This reflects gaps in communication services provided by pharmacies. Community pharmacies should offer periodic education for their customers regarding safe medication disposal practices through mailers, bag inserts, newsletters and face-to-face communication. Appropriate learning aids such as graphics, written material and audiovisual resources like videos may also be used.

Using the soon-to-expire stock first, multidisc vials, centralizing disposal of physician's samples and avoiding unnecessary prescribing are other practices that will 
contribute to decreased generation of waste. Though pharmacists' lack of knowledge is a challenge to be overcome, yet by taking an active role in drug management, pharmacists can positively impact patient outcomes and their communities as a whole.

\section{Limitations}

Weakness of our study includes small sample size; convenience sample may not be representative of the population under study (pharmacists), so a generalization cannot be made. The response rate was low. An accurate data collection is difficult as this is a sensitive topic, and social desirability response may have affected the validity of the results, leading to underestimation of the extent of inappropriate disposal. Moreover, self-reported data is subject to recall bias and is thus a confounding factor.

More such studies are warranted to precisely quantify drugs disposed in communities in order to expose the extent of this problem as they form the basis for identifying opportunities and setting targets for waste minimization, reuse and recycling, and cost reduction. Nonetheless, the study gives an insight into a problem that has not been given the importance it deserves, as proper disposal of medications can help to reduce environmental load of drugs.

\section{CONCLUSION}

Environmental pollution by improperly disposed pharmaceuticals is increasingly being recognized as a major threat to ecosystems worldwide. Pharmacists are accountable for pharmaceutical waste in their pharmacy; they should be updated about recommended drug disposal techniques and be a part of the solution to the problem of medication waste. There is need for national guidelines and a formalized protocol for disposal and destruction of unused and expired medications to minimize their potential impact on the environment. Pharmacists can make a difference regarding this issue that affects both the public health and the environment.

\section{ACKNOWLEDGMENTS}

The authors wish to thank the pharmacists who participated in the survey.

\section{REFERENCES}

1. Medicine Waste UK. Available from: http://www.medicinewaste.com. [Last cited on 2014 Apr 15].
2. Poorest US states rank among most wasteful in. Available from: http:// www.prnewswire.com/./poorest-us-states-rank-among-most-wasteful-in. [Last cited on 2014 Apr 15].

3. Over 1 million tones medical waste headache for India. Available from: http://www.thepharmatimes.in/./237-over-1-million-tonnes-medicalwaste-he. [Last cited on 2014 Apr 15].

4. Daughton CG. Drugs and the Environment: Stewardship and Sustainability. Las Vegas, Nevada: National Exposure Research Laboratory, Environmental Sciences Division, US EPA, Report NERL - LV-ESD 10/081, EPA/600//R-10/106; 12 Sept, 2010. 196 pp. Available from: http:// www.epa.gov/nerlesd1/bios/daughton/APM200-2010.pdf. [Last cited on 2014 Apr 16].

5. Cantrell L, Suchard JR, Wu A, Gerona RR. Stability of active ingredients in long-expired prescription medications. Arch Intern Med 2012;172:1685-7.

6. Ramaswamy BR, Shanmugam G, Velu G, Rengarajan B, Larsson DG. GCMS analysis and ecotoxicological risk assessment of triclosan, carbamazepine and parabens in Indian rivers. J Hazard Mater 2011;186:1586-93.

7. Brodin T, Fick J, Jonsson M, Klaminder J. Dilute concentrations of a psychiatric drug alter behavior of fish from natural populations. Science 2013;339:814-5.

8. Thomas MA, Klaper RD. Psychoactive pharmaceuticals induce fish gene expression profiles associated with human idiopathic autism. PLoS One 2012; 7:e32917.

9. Guidelines for safe disposal of unwanted pharmaceu. Available from: http:// www.who.int/water_sanitation_health/medicalwaste/unwantpharm.pdf. [Last cited on 2014 Apr 21].

10. How to dispose of unused medicines. FDA Consumer Health Information. Available from: http://www.fda.gov/for consumers/consumerupdates/ ucm101653.htm. [Last cited on 2014 Mar 23].

11. Wiedenmeyer K, Summers RS, Makie CA, Gous AG, Everard M. New paradigm for pharmacy practice. In: Developing Pharmacy Practice: A Focus on Patient Care. Geneva, Switzerland: WHO Department of Medicine Policy and Standards; 2006. p. 16.

12. Abahussain E, Waheedi M, Koshy S. Practice, awareness and opinion of pharmacists toward disposal of unwanted medications in Kuwait. Saudi Pharm J 2012;20:195-201.

13. Tong AY, Peake BM, Braund R. Disposal practices for unused medications in New Zealand community pharmacies. J Prim Health Care 2011;3:197-203.

14. Jarvis CI, Seed SM, Silva M, Sullivan KM. Educational campaign for proper medication disposal. J Am Pharm Assoc 2009;49:65-8.

15. Colborn T, vom Saal FS, Soto AM. Developmental effects of endocrinedisrupting chemicals in wildlife and humans. Environ Health Perspect 1993;101:378-84.

16. Yang TH, Scolaro KL, Dinkins MM. Raising awareness of medication disposal in professional schools. J Am Pharm Assoc 2010;50:444.

17. Kaye L, Crittenden J, Gressitt S. Executive summary: Reducing prescription drug misuse through the use of a citizen mail-back program in Maine. Available from: http://www.epa.gov/aging/RX-report-Exe-Sum/. [Last cited on 2014 Apr 21].

18. Medicine Disposal/Association of New Jersey Household. Available from: http://www.njhazwaste.com/hot-topics/medicine-disposal/. [Last cited on 2014 Apr 21].

19. Federal Register/Medicare Program; Contract Year, 2015. Available from: https://www.federalregister.gov/./medicare-program-contract-year-2015. [Last cited on 2014 Apr 22].

20. Paterson JM, Anderson GM. "Trial” prescriptions to reduce drug wastage: Results from Canadian programs and a community demonstration project. Am J Manag Care 2002;8:151-8.

21. Managing Pharmaceutical Waste - ASHP Advantage. Available from: http:// www.ashpadvantage.com/docs/PharmaWaste-Discussion-Guide.pdf. [Last cited on 2014 Apr 21].

22. Seehusen DA, Edwards J. Patient practices and beliefs concerning disposal of medications. J Am Board Fam Med 2006;19:542-7. 